\title{
Through-bolt push out effects on the behavior of hybrid masonry systems
}

\author{
Mihaela Nistor ${ }^{\mathrm{a}}$, Zhenjia Gao ${ }^{\mathrm{a}}$, Ilinca Stanciulescu ${ }^{\mathrm{a}, *}$ \\ ${ }^{a}$ Rice University, Department of Civil and Environmental Engineering, 6100 Main \\ Street, Houston, TX, 77005, U.S.A
}

\begin{abstract}
This paper provides specifications necessary for designing hybrid masonry systems that resist through-bolt push out effects. Hybrid masonry is a relatively new structural system that can be used in seismic areas and comprises masonry panels connected to frames through steel plate connectors. However, masonry break-out at the connection between the steel plates and the masonry panel requires further analysis to better understand the load transfer mechanism of the hybrid masonry system. Therefore, we use a computational framework to model the hybrid masonry that uses a typical plasticity model with hardening for the steel components and a nonlocal two-scalar damage model that accounts for tension and compression for the masonry panel. Based on parametric studies conducted using this framework
\end{abstract}

\footnotetext{
*Corresponding author. Tel.: +1713 348 4704; fax: +1713 3485268.

Email address: ilinca.s@rice.edu (Ilinca Stanciulescu)
} 
we provide recommendations for the through-bolt location and for the reinforcement percentage and location within the masonry panel to achieve best results in the load transfer mechanism of the hybrid masonry system during a seismic event.

Keywords: Hybrid masonry system, through-bolt, nonlocal-damage model

\section{Introduction}

This paper establishes a computational framework that facilitates the analysis of through-bolt push out effects on the maximum load taken by hybrid masonry systems. Current codes provide specifications regarding reinforcement requirements and details for masonry structures [1], but these specifications require further studying to understand the behavior of hybrid masonry systems subjected to through-bolt push out. The primary issue is how to model the masonry panel such that the capabilities of the hybrid masonry system and the damage propagation within the masonry panel are accurately predicted. Since the masonry panels in the hydrid masonry systems are built of concrete masonry unit blocks, a two scalar nonlocal continuum damage model [2] that treats the masonry wall as a homogenized mixture of mortar, grout and concrete blocks is adopted and the reinforcement is modelled as a separate component. Homogenization techniques for 
older masonry types (e.g. [3 5]) are also available in the literature. Experimental data [6, 7] is used to calibrate and validate the numerical model. Finally, parametric studies of though-bolt push out show that the through-bolt location and the reinforcement percentage and location within the masonry panel are important factors that influence the behavior of hybrid masonry systems.

The behavior of reinfored concrete masonry walls subjected to in-plane loading has long been of interest to researchers and practitioners that were looking into methods for using masonry in seismic regions not only as load bearing components of the structural system, but also as energy dissipating components. Experimental tests and numerical modeling (see [8-11] and the references therein) show the performance of such walls and provide guidelines to achieve optimal results for in-plane loaded reinforced masonry walls.

Moreover, new technologies such as hybrid masonry have emerged to accommodate for design requirements in moderate to high seismic areas [12]. The hybrid masonry system consists of a steel or reinforced concrete frame surrounding reinforced masonry panels and connector plates that transfer part of the loading from the frame to the masonry panel (Figure 1). In addition to providing spatial functionality in a building, the panels also enhance 
the seismic performance. However, as stated by Eidini et al. [13] successful implementation of the hybrid masonry system requires validation of robust steel-masonry interface behavior and global performance of the system.

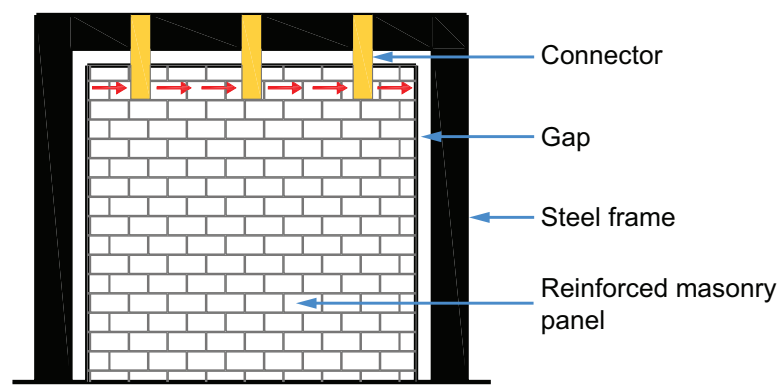

(a) Components of the hybrid system

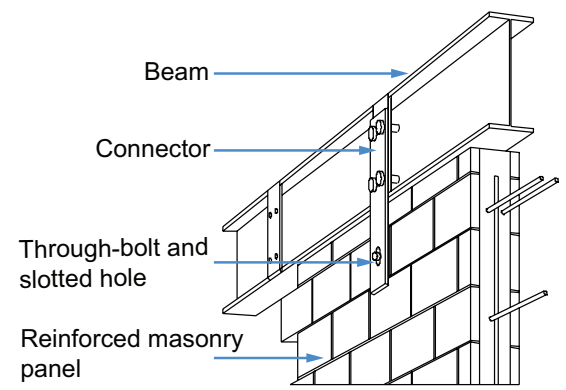

(b) Detail of wall-beam connection

Figure 1: Type I hybrid masonry system

The reinforced masonry panels are a component of the hybrid masonry system. The masonry breakout failure mechanism at the connection between the masonry panel and the connector is crucial for the overall performance of hybrid masonry systems. This paper focuses on the through-bolt push out effects on the masonry panels, because it has been found that through-bolt location and the reinforcement layout influence significantly the maximum capacity of the panel.

Depending upon how the reinforced masonry panel is constructed, the transmission of loads between frame and wall happens through a variety of mechanisms, corresponding to systems classified as type I, II and III [14]. 
The type I hybrid wall allows only for the transfer of horizontal forces, which are transmitted from the beam to the wall through the connectors. The gap between the wall and the frame prevents axial load and in-plane shear at columns to be transferred from the frame to the masonry panel (see Figure 1). The type II hybrid wall is constructed with no gap between the beam and the top of wall and thus, besides the horizontal forces from type I, vertical contact pressures can be transferred from the beam to the wall and additional horizontal forces can be transferred through friction. The type III hybrid wall has no gaps between the frame and the reinforced masonry, which leads to transmission of forces between columns and panels as well.

Experimental tests [6, 7] have shown that type III walls have a less ductile failure mechanism, while type I and type II walls presented failure mechanisms that are appropriate to use in medium and high seismic areas. Since it is of interest to utilize the hybrid masonry systems in medium to high seismic regions and because the experimental data available is for type I, in this paper type I walls are the focus of the investigation.

A computational framework that correctly predicts the capability of the hybrid masonry system and the damage propagation in the masonry panel needs to be established in order to make use of this new technology. The 
computational framework has to take into account each component of the hybrid masonry system. Modeling the steel components is straightforward and typical steel models are adequate. In contrast, modeling a masonry panel is a challenging task because difficulties arise from the quasi-brittle behavior of concrete hollow blocks that are used for the masonry panels. Since concrete has very high compressive strength, but very low resistance in tension, size effects, tension softening, tension hardening, tension stiffening, bond-slip, concrete confinement, creep and other non-linear effects have a substantial impact on the structural behavior and need to be accounted for in the simulations of such structures.

In finite element analyses, several approaches are available to model damage in concrete due to tension. In this work a continuum damage mechanics formulation is utilized to capture the damage distribution and propagation in the masonry panel. This approach captures the material degradation due to micro cracking, interfacial de-bonding and other similar defects [15], along with changes in the microstructure that lead to a degradation of material stiffness observed on the macro scale. A two scalar damage model [2] that accounts for damage in tension and compression is implemented in both local and nonlocal form. The local formulation suffers from damage localization 
and leads to numerical results that exibit pathological sensitivity to the mesh size. To overcome these difficulties the nonlocal formulation is adopted. Re-

cently, a new model [16] based on the same original model from Mazars [17] was proposed to forecast the behavior of concrete under severe loadings and to capture unilateral effects. Its new features are not relevant for the loading scenarios simulated here that are captured well by the previous models, therefore it was not adopted in this work.

The rest of the paper is organized as follows: Section 2 describes the experimental setup, introduces the numerical model and the procedure to calibrate its parameters, and compares the numerical results against experimental data; Section 3 presents results from the parametric studies conducted to assess the influence of reinforcement and of the through-bolt location on the behavior of the hybrid masonry system; and Section 4 summarizes the findings.

\section{Modeling of the hybrid masonry system}

The experimental data used for the calibration of the damage model was obtained in experiments conducted at the University of Hawaii at Manoa (UHM), whose aim was to study the through-bolt push out effects [6, 7]. The 
experiments at UHM were part of a larger research project, which also included large-scale experiments (University of Illinois at Urbana-Champaign) and studied the applicability of the hybrid masonry systems in moderate and high seismic regions. The experimental data is available in the NEES repository at https://nees.org/warehouse/project/917.

Six reinforced masonry walls with different percentage and location of horizontal reinforcement and through-bolt positioning in the masonry panel have previously been constructed and tested [6]. A typical wall specimen and details on the frame-wall connection are shown in Figure2, A wide flange beam supported by two pin-ended load rods lies 1 in. $(25.4 \mathrm{~mm})$ above the concrete masonry unit wall and transfers horizontal loads from the hydraulic actuator through the connector plates to the wall. A single through-bolt and double link plates (one link plate on each side of the masonry wall) are used. The link plates have the strength to transfer full story shears to masonry panels without yielding. The simplified schematics for the typical wall is shown in Figure 3 .

The masonry panel is fully grouted, built of standard 8 in. $\mathrm{x} 8$ in. $\mathrm{x} 16$ in. (203.2 mm x $203.2 \mathrm{~mm}$ x $406.4 \mathrm{~mm}$ ) concrete masonry unit blocks and is five blocks long $(2.03 \mathrm{~m})$ and four courses high $(0.81 \mathrm{~m})$. The wall is reinforced 


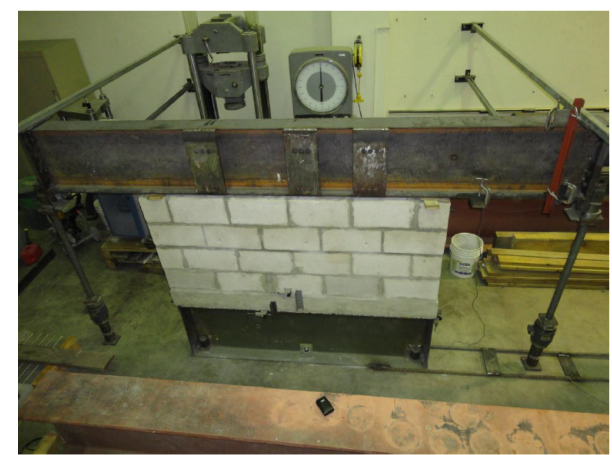

(a) Steel frame and reinforced masonry wall

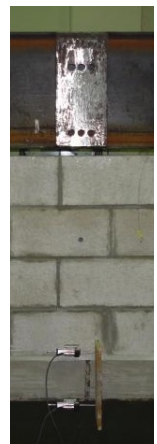

(b) Zoom in

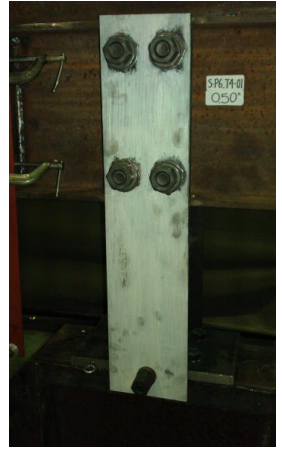

(c) Link plate

Figure 2: Experimental setup for Type I hybrid masonry system (Images courtesy of University of Hawaii at Manoa)

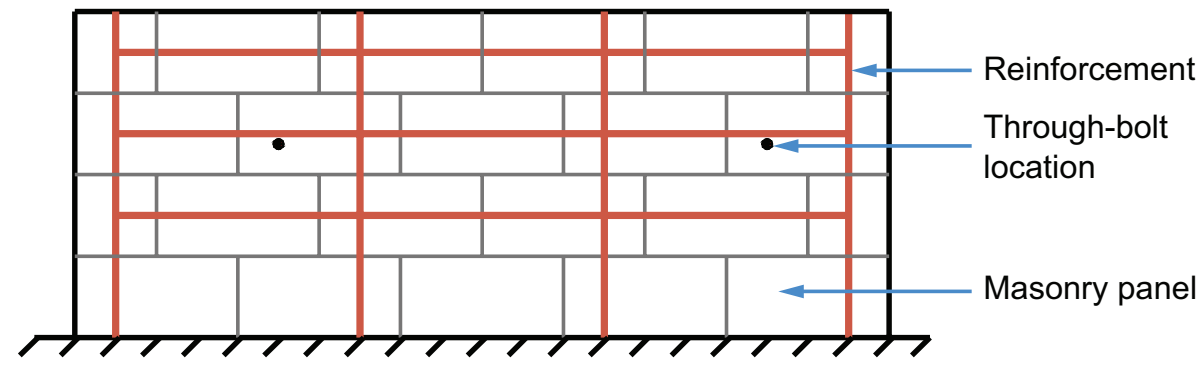

Figure 3: Model of masonry panel with reinforcement layout and bolt locations

with bars \#4 (M\#13) ASTM steel grade 60 without joint reinforcing. The vertical reinforcement is spaced at $24 \mathrm{in} .(610 \mathrm{~mm})$, and the first bar is placed in the middle of the first cell of the concrete masonry unit block (Figure 3). The horizontal reinforcement varies from either one bar in the top course or in the second course from the top to three bars distributed in the top three courses or two bars in the second course from top.

The walls were tested twice. In the first test (test 1), the through- 
bolt connecting the masonry panel to the conector plates is positioned in the second cell $12 \mathrm{in.}(300 \mathrm{~mm})$ from the edge of the masonry panel and displacement control loading is applied on the beam of the frame. Since the bolt is located close to the edge, it is assumed that only half of the wall is damaged and therefore another test was performed on the undamaged half. In the second test (test 2) the through-bolt is located in the third cell $20 \mathrm{in}$. (500 mm) from the edge. Monotonic load-displacement curves are available for each of the walls, where the load represents the horizontal force taken by the masonry panel and displacement is the measured relative displacement of the through-bolt to the wall.

The experimental tests [6, 7] showed that the through-bolt should be located at least in the second course from the top, as this ensures a greater capacity for the masonry panel and a ductile failure. Additionally, experimental tests indicated that increasing the distance from the edge to the through-bolt location ensures a substantial increase in the capacity of the wall. Adding a bond beam above and below the through-bolt also increases the capacity of the wall.

Based on the data available from experimental tests, the computational model is simplified to a reinforced masonry wall that has fixed base, with 
displacement control applied at the through-bolt location. The experimental data provides enough information to verify that the model accurately captures damage distribution and the capacity of the masonry panel. FEAP (Finite Element Analysis Program, [18]) is used for the implementation of the computational model. The formulations for the components of the computational model of the hybrid masonry system are a mix of FEAP original elements and user implemented functions.

Since the computational model is simplified to the reinforced masonry panel, the only steel components that need to be modeled are the reinforcement bars. The two-dimensional frame element based on elasto-plastic model available in FEAP is used for modeling the reinforcement steel bars. The yield function for the elasto-plastic model is [18]:

$$
f\left(\varepsilon^{p}\right)=\left|\sigma_{d e v}-\frac{2}{3} H_{k i n} \dot{\varepsilon}^{p}\right|-\left[\sigma_{Y \infty}+\left(\sigma_{Y 0}-\sigma_{Y \infty}\right) e^{-\beta_{s} \varepsilon^{p}}+H_{i s o} \varepsilon^{p}\right],
$$

where $\beta_{s}$ is a delay constant that controls the speed at which the material transitions from elasticity to plasticity, $H_{i s o}$ is the isotropic hardening modulus, $H_{k i n}$ is the kinematic hardening modulus, $\sigma_{Y 0}$ is the yield stress, $\sigma_{Y \infty}$ is the ultimate stress, $\varepsilon^{P}$ is the plastic strain and $\sigma_{d e v}$ is the deviatoric stress. 
The infinitesimal plastic strain increment is found from the flow rule:

$$
\dot{\varepsilon}^{p}=\dot{\gamma} \frac{\partial f}{\partial \sigma}
$$

where $\dot{\gamma}$ is the plastic consistency parameter rate $(\dot{\gamma}=0$ for elastic behavior and $\dot{\gamma}>0$ for plastic behavior). Table 1 summarizes the input values required by FEAP for this element. Note that $\nu$ represents Poisson's ratio. Experimental tensile tests on the reinforcement bars are used to calibrate $\beta_{s}$, $H_{i s o}, H_{k i n}$, the yield stress, the ultimate stress and Young's modulus (values listed in Table 1).

\begin{tabular}{|c|c|c|c|c|c|c|}
\hline $\begin{array}{c}\text { Yield stress } \\
\left(\mathrm{N} / \mathrm{m}^{2}\right)\end{array}$ & $\begin{array}{c}\text { Ultimate stress } \\
\left(\mathrm{N} / \mathrm{m}^{2}\right)\end{array}$ & $\begin{array}{c}\text { Young's modulus } \\
\left(\mathrm{N} / \mathrm{m}^{2}\right)\end{array}$ & $\nu$ & $\beta_{s}$ & $H_{\text {iso }}$ & $H_{\text {kin }}$ \\
\hline $5.07 \times 10^{8}$ & $8.07 \times 10^{8}$ & $2.09 \times 10^{11}$ & 0.3 & 45 & 0 & $1.2 \times 10^{8}$ \\
\hline
\end{tabular}

Table 1: Characteristics of reinforcement bars ASTM steel grade 60 calibrated from tensile tests (input parameters required in FEAP for the element that accounts for plasticity with hardening).

A two scalar damage model [2, 17, 19] in nonlocal two-dimensional form with plane stress assumption is adopted to model the masonry. The model is designed to capture damage of brittle materials (in a continuum damage approach) in both tension and compression, with model parameters that are designed to provide a homogenized description of what is in reality a process 
in a composite material. The constitutive law is written in the form:

$$
\boldsymbol{\sigma}=(1-\omega) \boldsymbol{D} \boldsymbol{\varepsilon}
$$

where $\boldsymbol{\sigma}$ is the stress, $\boldsymbol{\varepsilon}$ the strain, $\boldsymbol{D}$ is the elastic material stiffness tensor, and $\omega$ is the damage variable. When the material is totally damaged $\omega=1$, while for the undamaged state $\omega=0$.

The responses from tension and compression are coupled by the two scalar damage model. The total damage coefficient $\omega$ is defined as the weighted average of the damage coefficients for tension $\left(\omega_{t}\right)$ and compression $\left(\omega_{c}\right)$ :

$$
\omega=\alpha_{t}^{\beta} \omega_{t}+\alpha_{c}^{\beta} \omega_{c}
$$

where weights $\alpha_{t}$ and $\alpha_{c}$ are functions of the principal strains $\varepsilon_{I}=\varepsilon_{c i}+\varepsilon_{t i}$ :

$$
\begin{aligned}
\alpha_{t} & =\sum_{i=1}^{3} H_{i} \frac{\varepsilon_{t i}\left(\varepsilon_{c i}+\varepsilon_{t i}\right)}{\bar{\varepsilon}^{2}} \\
\alpha_{c} & =\sum_{i=1}^{3} H_{i} \frac{\varepsilon_{c i}\left(\varepsilon_{c i}+\varepsilon_{t i}\right)}{\bar{\varepsilon}^{2}}
\end{aligned}
$$

The strain due to positive stress is $\varepsilon_{t i}$, while $\varepsilon_{c i}$ is the strain due to negative stress, $\bar{\varepsilon}$ is the equivalent strain, $\beta$ is a factor that is used to reduce the effect 
of damage under shear force, and the parameter $H_{i}$ is equal to 1 when $\varepsilon_{I} \geq 0$ and equal to 0 otherwise.

The equivalent strain is defined as:

$$
\bar{\varepsilon}=\sqrt{\sum_{I=1}^{3}<\varepsilon_{I}>^{2}}
$$

where $\varepsilon_{I}, I=1,2,3$ are the principal strains, and the brackets $<\cdot>$ denote the positive part of the quantity.

The damage coefficient for compression $\omega_{c}$ has the form given in the original model [17]:

$$
\omega_{c}= \begin{cases}0 & \text { if } \kappa \leq \varepsilon_{0} \\ 1-\frac{\varepsilon_{0}\left(1-A_{c}\right)}{\kappa}-\frac{A_{c}}{e^{B_{c}\left(\kappa-\varepsilon_{0}\right)}} & \text { if } \varepsilon_{0} \leq \kappa,\end{cases}
$$

while to better capture the behavior of masonry in tension [20] the damage coefficient for tension $\omega_{t}$ is evaluated as:

$$
\omega_{t}= \begin{cases}0 & \text { if } \kappa \leq \varepsilon_{0} \\ 1-\frac{\varepsilon_{0}}{\kappa} e^{-\frac{\kappa-\varepsilon_{0}}{\varepsilon_{f}-\varepsilon_{0}}} & \text { if } \varepsilon_{0} \leq \kappa \leq \varepsilon_{f},\end{cases}
$$


where $\kappa$ is the largest equivalent strain obtained in the history of loading, $\varepsilon_{0}$ is the initial damage threshold and $\varepsilon_{f}$ is a parameter controlling the post-peak slope (the softening branch) of the stress-strain curve for uniaxial tension. The remaining parameters $A_{c}$ and $B_{c}$ are parameters that have no direct physical meaning.

The resulting computational model for masonry requires calibration of all parameters for it to have predictive capabilities. Ideally, a variety of experimental tests provide the data necessary to calibrate the parameters in damage models. Unfortunately, only limited experimental data is available in general, making the parameter calibration a challenging process. The eight parameters that need to be calibrated are $E_{m}$ (modulus of elasticity for masonry), $\varepsilon_{0}$ (initial damage threshold), $\nu$ (Poisson's ratio), $\varepsilon_{f}, A_{c}, B_{c}, \beta$, $l_{R}$ (characteristic length). They interact in complex ways and influence the global response.

In this paper parameters $E_{m}, \nu, \varepsilon_{0}, \varepsilon_{f}, A_{c}, B_{c}, \beta$ and $l_{R}$ are calibrated to capture the average behavior of the full-system experimentally tested (see short description of the experimental data at the beginning of this section). For average values of the concrete masonry blocks, grout and mortar the reader is referred to the experimental data available in [6]. The number of 
parameters that require calibration is reduced via constraints imposed on the constitutive behavior. One relationship can be determined between $A_{c}, B_{c}$ and $\varepsilon_{0}$ by requiring that the uniaxial compressive stress-strain curve has a continuous variation of slope [21]:

$$
A_{c} B_{c} \varepsilon_{0}=A_{c}-1
$$

and another relationship by ensuring that the same stress-strain curve has a round and convex peak:

$$
A_{c}=\frac{B_{c}\left(E_{m} \varepsilon_{0}-f_{c} \nu\right)}{E_{m}\left(B_{c} \varepsilon_{0}-e^{-1+B_{c} \varepsilon_{0}}\right)} .
$$

Table 2 shows the calibrated values for the "local" parameters of the two scalar damage model. All walls are modeled using these parameters. The only parameter that varies from wall to wall and from test 1 (bolt located $300 \mathrm{~mm}$ from wall edge) to test 2 (bolt located $500 \mathrm{~mm}$ from wall adge) is the characteristic length $l_{R}$, i.e., the size of the nonlocal domain, which is found to depend on the location of the through-bolt and on the reinforcement distribution.

The three walls among the ones experimentally tested [6, 7] chosen to 


\begin{tabular}{|c|c|c|c|c|c|c|c|}
\hline $\begin{array}{c}E_{m} \\
\left(\mathrm{~N} / \mathrm{m}^{2}\right)\end{array}$ & $\nu$ & $\begin{array}{c}f_{c} \\
\left(\mathrm{~N} / \mathrm{m}^{2}\right)\end{array}$ & $A_{c}$ & $B_{c}$ & $\varepsilon_{0}$ & $\varepsilon_{f}$ & $\beta$ \\
\hline $1.1 \times 10^{9}$ & 0.2 & $22.3 \times 10^{6}$ & 1.065 & 101.721 & 0.0006 & 0.004 & 1.14 \\
\hline
\end{tabular}

Table 2: Calibrated parameters for the damage model.

demonstrate the calibration of the model have the same vertical reinforcement, i.e., four \#4 (M\#13) vertical bars spaced at 24 in. (610 mm), starting 4 in. (100 mm) away from the edge of the wall. Wall W1 (FGW-1\#4TBB in the experimental data [6]) has one \#4 (M\#13) horizontal bar located in the top course and the through-bolt located in the same course under the horizontal bar. Wall W2 (FGW-2\#4BB) has two \#4 (M\#13) bars positioned in the second course from top and the through-bolt under the horizontal bar in the second course. Wall W3 (FGW-3\#4BB) contains the most horizontal reinforcement, three \#4 (M\#13) bars with one in each course starting from the top, and the through-bolt in the second course below the horizontal bar. Table 3 summarizes the horizontal reinforcement characteristics and also provides the denomination in the experimental data [6] for each of the three walls.

\begin{tabular}{|c|c|c|c|}
\hline Wall & Experimental specimen & Horizontal reinforcement & Location \\
\hline W1 & FGW-1\#4TBB & $1 \# 4(\mathrm{M} \# 13)$ & top course \\
\hline W2 & FGW-2\#4BB & $2 \# 4(\mathrm{M} \# 13)$ & second course \\
\hline W3 & FGW-3\#4BB & $3 \# 4(\mathrm{M} \# 13)$ & top three courses \\
\hline
\end{tabular}

Table 3: Horizontal reinforcement bars in walls used to exemplify model calibration 
The location of the through-bolt where the load is applied is an important factor when choosing the $l_{R}$ value. The area that contributes to the nonlocal algorithm increases as the distance from the edges to the throughbolt increases. Also, when the horizontal reinforcement is distributed in the masonry wall, the area contributing to the nonlocal formulation decreases because the vertical and the horizontal reinforcement create a grid with bars acting as edges of the nonlocal domain of influence.

From the calibration process the characteristic length is determined first for the walls in test 1 . For wall W1 that has only one horizontal reinforcement in the top course, the characteristic length is found to be $l_{R}=0.065 \mathrm{~m}$. In the case of wall W2 that has two horizontal reinforcement bars both located in the second course from top, the distance from the through-bolt to the top edge increased compared to that in wall $\mathrm{W} 1$ and the characteristic length increased as well to $l_{R}=0.11 \mathrm{~m}$. For wall $\mathrm{W} 3$ the horizontal reinforcement is distributed in the top three courses, creating with the vertical reinforcement bars a finer grid than in the previous cases. The characteristic length is found to be $l_{R}=0.1 \mathrm{~m}$, smaller than in the case when the horizontal bars are located in the second course from top, but larger than the case when a bar is located in the top course. 
The characteristic length $l_{R}$ for each of the three walls in test 2 is found to be $0.1 \mathrm{~m}$ for wall $\mathrm{W} 1,0.16 \mathrm{~m}$ for wall $\mathrm{W} 2$ and $0.15 \mathrm{~m}$ for wall $\mathrm{W} 3$, approximately a $50 \%$ increase from test 1 , consistent with the increase of the distance between the bolt location and the edge of the masonry wall. The tests run with specified parameters and corresponding characteristic length showed good agreement with the experimental data (Figure 4).

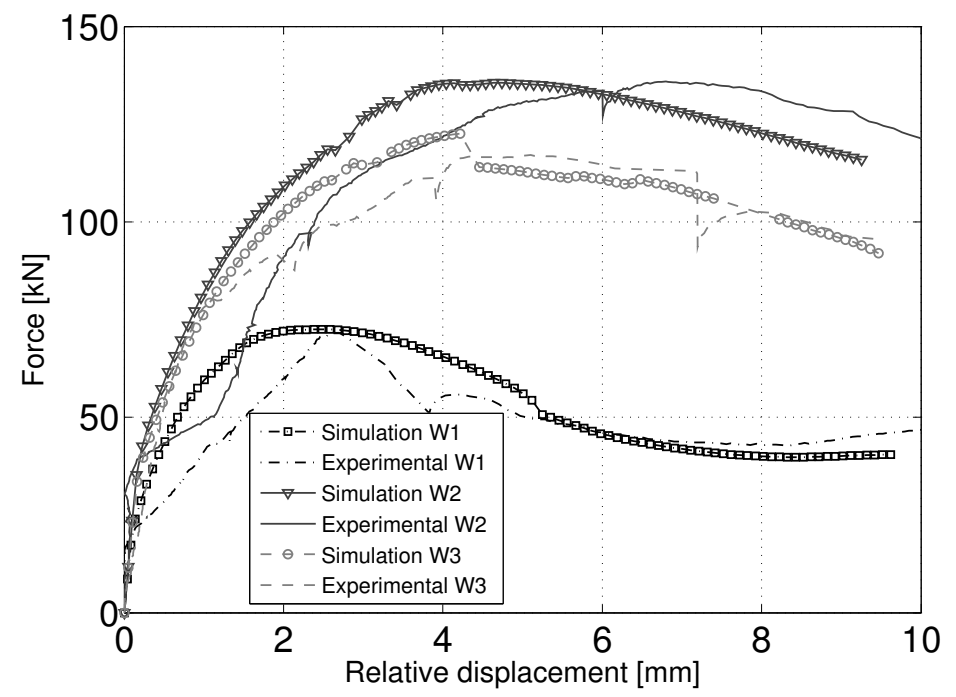

Figure 4: Numerical and experimental tests for three walls in test 1.

The good agreement between the experimental data and the simulation results make the calibrated model a useful tool for further simulations. In what follows the authors of this paper discuss various findings based on parametric studies performed with this model. 


\section{Parametric studies}

In the previous section the nonlocal damage model is calibrated. Once the computational framework is set and the model can capture accurately the capablities of the masonry panel, it is of interest to conduct additional parametric studies that are designed to provide information necessary to assess the performance of hybrid masonry systems when subjected to through-bolt push out. Based on the results of the parametric studies recommendations for the through-bolt location and reinforcement percentage and layout are provided.

The walls chosen for the parametric studies use the reinforcement layouts described in Table 3. In each simulation the through-bolt location and the diameters of the vertical and horizontal reinforcement bars vary. The through-bolt is located either in the second cell $(300 \mathrm{~mm})$ or in the third cell $(500 \mathrm{~mm})$ from the edge of the masonry panel and we refer to test 1 when the through-bolt is located in the second cell and test 2 when the throughbolt is in the third cell. The vertical and horizontal reinforcement diameters are varied between \#5 $(\mathrm{M \# 16)}$ and \#11 (M\#36) by specifying two bar diameters, one for all vertical bars, and one for all horizontal bars. The diameter range considered is consistent with specifications for masonry walls 
in medium seismic regions [1].

To quantify the contribution of reinforcement on the capacity of the masonry panel, the three walls considered were first tested without reinforcement, then only with vertical reinforcement, and finally only with horizontal reinforcement. The results were compared to their initial configuration that has both vertical and horizontal bars with dimensions given in Table 3. The maximum horizontal force taken by the masonry for each of the walls in all cases is shown in Figure 5. As expected, the unreinforced walls had the lowest capacity. Adding only vertical reinforcement to the walls did not bring an increase in the maximum capacity. The walls with only horizontal reinforcement had a significant improvement in the maximum capacity when compared with the previous two cases. The best results are achieved when both horizontal and vertical bars are used and a reinforcing grid is created. These results are in agreement with findings by Haach et al. [11] and by Tomazevic [22], which point out that the vertical reinforcement does not contribute to the shear resistance of the walls unless confined by horizontal reinforcement. The influence of vertical reinforcement diameter and of horizontal reinforcement diameter are analyzed next.

Parametric studies show that for a given wall configuration and for any 


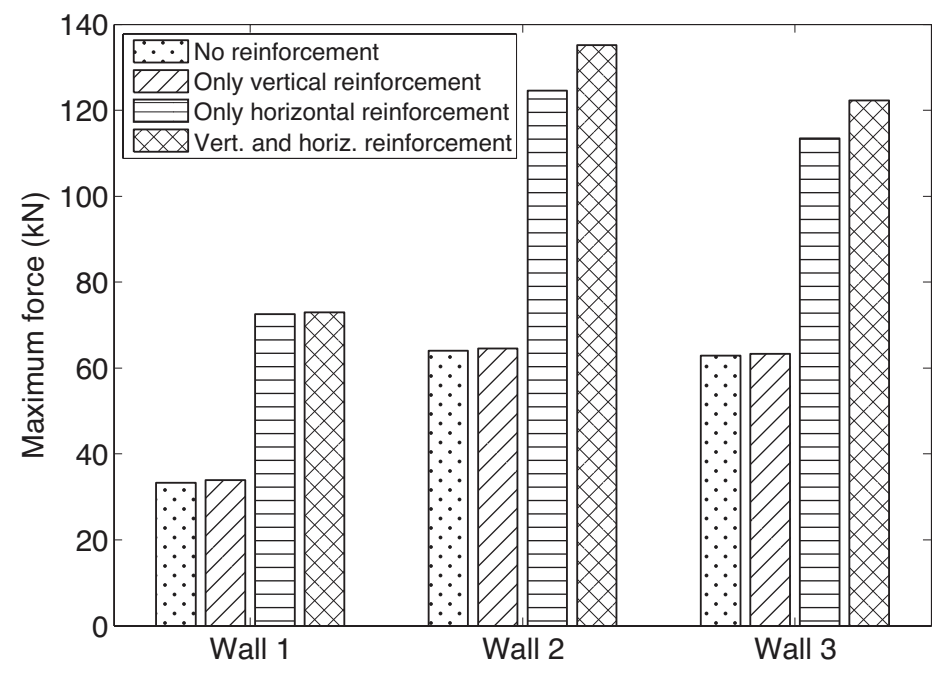

Figure 5: Maximum force taken by masonry panels with various reinforcement layout in test 1 (more than $50 \%$ increase in maximum force from unreinforced masonry panels to the panels with vertical and horizontal reinforcement)

horizontal bar diameter, the vertical reinforcement does not influence significantly the capacity of the masonry panel. Although the vertical reinforcement diameter ranges from \#5 (M\#16) to \#11 (M\#36), there is a difference of at most $2.5 \%$ in the maximum capacity for walls in test 1 and of at most $3 \%$ for the walls in test 2 . This indicates that the vertical reinforcement is important because it creates a grid with the horizontal reinforcement that helps in carrying and distributing the load, but similar results in the maximum capacity are achieved regardless of the vertical reinforcement diameter. Figure 6 illustrates the percentage increase in the maximum force for each wall at all horizontal reinforcement diameters when varying the vertical re- 
inforcement diameters in test 1.

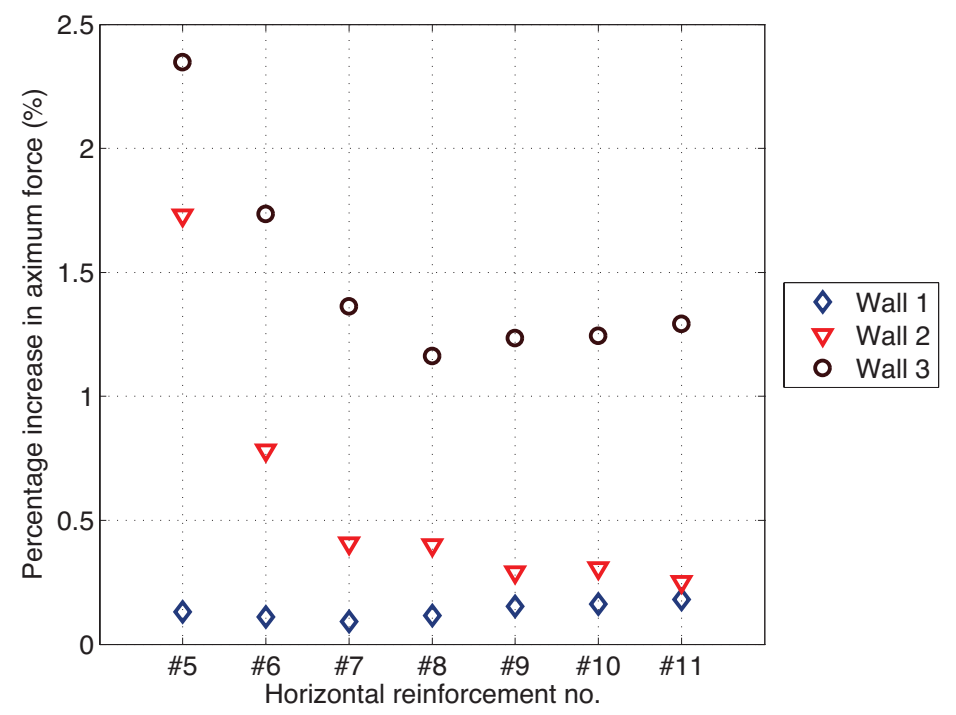

Figure 6: Percentage increase in maximum force at specific horizontal bar diameters when varying the vertical reinforcement diameter from \#5 (M\#16) to \#11 (M\#36) in test 1.

Analyzing the influence of the horizontal reinforcement diameter, it is found that although the horizontal reinforcement with minimum diameter brings a significant improvement in the maximum capacity of the wall when compared to the unreinforced wall, increasing the diameter has a contribution on the maximum capacity that saturates rapidly. This rapid saturation suggests that the limitation of the reinforcement diameter to \#11 (M\#36) that is arbitrarily chosen in MSJC [1] is justified. For example, in Figure 7 corresponding to walls in test 1 , the lowest values for the maximum force for each of the walls belong to the unreinforced walls. The other values represent 
the maximum force for each of the walls when the vertical and the horizontal reinforcement diameters are varied. There is an important jump in the maximum force from unreinforced walls to the reinforced walls followed by a rapid saturation.

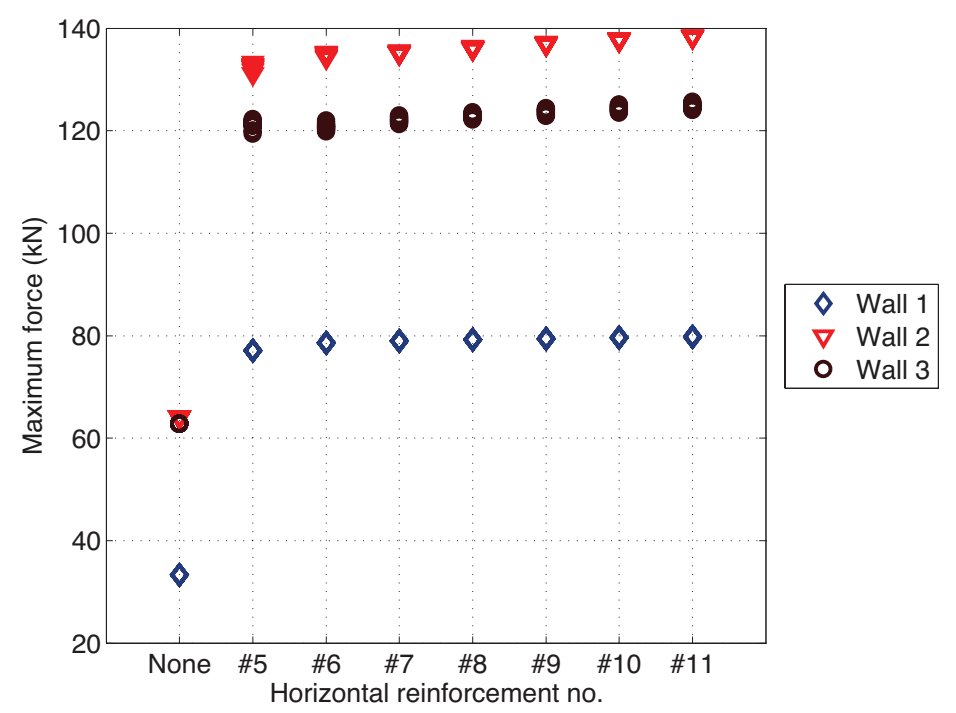

Figure 7: Maximum force taken by masonry panels for combinations of vertical and horizontal bars with various diameters and for unreinforced masonry panels in test 1 .

With this numerical study we confirm previous experimental results [23], which indicate that distributed reinforcement bars with smaller diameter provide better performance than fewer bars with a larger diameter. Also, the location of the through-bolt where the load is applied has proven to have significant influence on the resistance of the masonry panel. As discussed by Robertson et al. 24] the through-bolt should be located below the hor- 
izontal reinforcement in the bond beam. If this condition is not satisfied, damage localizes in a narrower area above the bond beam thereby reducing the capacity and the dissipated energy of the masonry panel. When the load is applied closer to an edge, the resistance is much smaller. Comparing the maximum force from the parametric studies in test 1 and test 2 confirms the results obtained experimentally and reported in [6, 7]. It is found that the maximum capacity when the load is applied in the third cell from the wall edge is $25 \%$ to $65 \%$ higher than in the case when it is applied in the second cell, depending also on the course in which it is located (i.e., when located in the second course from top the maximum capacity is higher than when applied in the top course). Thus, as the through-bolt is located farther from the wall edges, the maximum capacity increases.

\section{Conclusions}

This paper provides useful recommendations for the reinforcement layout and the location of the connectors in order to achieve optimal results for the global response of the hybrid masonry system.

We establish a computational framework to simulate the behavior of the hybrid masonry. In this framework we model the masonry panel via a two 
scalar nonlocal damage model. We demonstrate that all local parameters can be calibrated and additionally we correlate the nonlocal parameter $l_{R}$ with the location of the through-bolt (where load is applied) and with the reinforcement layout.

Parametric studies on the reinforcement diameters and layout show that the configuration and spacing of the reinforcement bars together with the location where the load is applied strongly influence the capacity of the masonry panel. As mentioned in MSJC [1] we found that the masonry panels with more distributed bars that have smaller diameter perform better than the ones that have fewer bars with larger diameters. The vertical reinforcement on its own does not contribute much to the overall response, but combined with the horizontal reinforcement it increases the capacity of the wall with more than $50 \%$. The horizontal reinforcement with minimum diameter brings a significant contribution to the capacity of the masonry panel, but the contribution saturates rapidly as the diameter is increased, indicating that using reinforcement bars with large diameters cannot efficiently increase the level of forces resisted by the masonry panel. The maximum force taken by the masonry panel increases when the through-bolt is located farther away from the edge of the panel. 
Finally, we conclude that the through-bolt push out effects on the behavior of hybrid masonry systems are controled by the through-bolt location and by the reinforcement percentage and layout in the masonry panel.

\section{Acknowledgements}

This work was partially funded by NSF-NEES under grant no. 0936464. The authors thank professor Ian Robertson and his research group at the University of Hawaii at Manoa for useful discussions and for sharing the experimental results for the small scale hybrid system testing.

\section{References}

[1] MSJC, Building Code Requirements and Specification for Masonry Structures, Containing TMS 402-11/ACI 530-11/ASCE 5-11, TMS 60211/ACI 530.1-11/ASCE 6-11, and Companion Commentaries, Masonry Standards Joint Committee, 2011.

[2] G. Pijaudier-Cabot, J. Mazars, J. Pulikowski, Steel-concrete bond analysis with nonlocal continuous damage, Journal of structural engineering

New York, N.Y. 117 (1991) 862-882. 
[3] R. Luciano, E. Sacco, Homogenization technique and damage model for old masonry material, International Journal of Solids and Structures 34 (1997) 3191-3208.

[4] A. Caporale, F. Parisi, D. Asprone, R. Luciano, A. Prota, Micromechanical analysis of adobe masonry as two-component composite: Influence of bond and loading schemes, Composite Structures 112 (2014) 254-263.

[5] A. Zucchini, P. B. Lourenço, A coupled homogenisation-damage model for masonry cracking, Computers \& structures 82 (2004) 917-929.

[6] J. Aoki, I. N. Robertson, Hybrid Masonry Connector Plate and Headed Stud Small-Scale Wall Testing, Research Report UHM/CEE 12-06, University of Hawaii at Manoa, HI, 2012. http://www.cee.hawaii.edu/ reports/UHM-CEE-12-06.pdf.

[7] G. Johnson, I. Robertson, Capacity of masonry loaded by through-bolts in double shear, The Masonry Society Journal (2015).

[8] P. Shing, M. Schuller, V. Hoskere, In-plane resistance of reinforced masonry shear walls, Journal of structural Engineering 116 (1990) 619640. 
[9] M. T. Shedid, R. G. Drysdale, W. W. El-Dakhakhni, Behavior of fully grouted reinforced concrete masonry shear walls failing in flexure: Experimental results, Journal of structural engineering 134 (2008) 17541767.

[10] V. G. Haach, G. Vasconcelos, P. B. Lourenço, Experimental analysis of reinforced concrete block masonry walls subjected to in-plane cyclic loading, Journal of structural engineering 136 (2009) 452-462.

[11] V. G. Haach, G. Vasconcelos, P. B. Lourenço, Parametrical study of masonry walls subjected to in-plane loading through numerical modeling, Engineering Structures 33 (2011) 1377-1389.

[12] D. T. Biggs, Hybrid Masonry Structures, Proceedings of the Tenth North American Masonry Conference, The Masonry Society, Boulder, CO (2007).

[13] M. Eidini, D. P. Abrams, L. A. Fahnestock, Seismic design and viability of hybrid masonry building systems, Journal of Structural Engineering 139 (2013) 411-421.

[14] NCMA, Hybrid concrete masonry design tek 14-9a, National Concrete Masonry Association (2009). 
[15] Y. Calayir, M. Karaton, A continuum damage concrete model for earthquake analysis of concrete gravity dam-reservoir systems, Soil Dynamics and Earthquake Engineering 25 (2005) 857-869.

[16] J. Mazars, F. Hamon, A New Model to Forecast the Response of Concrete Structures Under Severe Loadings: the $\mu$ Damage Model, VIII International Conference on Fracture Mechanics of Concrete and Concrete Structures (2012) 1-9.

[17] J. Mazars, Application de la mécanique de l'endommagement au comportement non linéaire et à la rupture du béton de structure, Ph.D. thesis, Universite Pierre et Marie Curie, Paris, France, 1984.

[18] R. Taylor, FEAP, a Finite Element Analysis Program: Version 8.3 User Manual (2011).

[19] J. Mazars, A description of micro- and macroscale damage of concrete structures, Engineering Fracture Mechanics 25 (1986) 729-737.

[20] M. Jirásek, Non-local damage mechanics with application to concrete, Revue française de génie civil 8 (2004) 683-707. 
[21] G. Hofstetter, G. Meschke (Eds.), Numerical Modeling of Concrete Cracking, 2011 ed., Springer, 2011.

[22] M. Tomazevic, Earthquake-resistant design of masonry buildings, World Scientific Publishing Company, 1999.

[23] M. Priestley, D. Bridgeman, Seismic resistance of brick masonry walls, NZ Pottery and Ceramics Research Institute, 1974.

[24] I. Robertson, G. Johnson, S. Mitsuyuki, J. Aoki, Ductile fuse connectors for hybrid masonry systems, in: Structures Congress, 2013, pp. 11591168. 